\title{
High expression of HEFI is associated with poor prognosis in urinary bladder carcinoma
}

This article was published in the following Dove Press journal:

OncoTargets and Therapy

21 July 2014

Number of times this article has been viewed

\author{
Qi Zhang' \\ Hui-Ju Wang ${ }^{2}$ \\ Da-Hong Zhang' \\ Guo-Qing $\mathrm{Ru}^{3}$ \\ Xu-Jun $\mathrm{He}^{2}$ \\ Ying-Yu $\mathrm{Ma}^{2}$ \\ 'Department of Urology, ${ }^{2}$ Key \\ Laboratory of Gastroenterology \\ of Zhejiang Province, ${ }^{3}$ Department \\ of Pathology, Zhejiang Provincial \\ People's Hospital, Hangzhou, \\ People's Republic of China
}

\begin{abstract}
Human enhancer of filamentation 1 (HEF1) is a multidomain scaffolding protein that has been thought to play an important role in the tumor progression of various cancers. HEF1 expression has not previously been reported in urinary bladder carcinoma, and little is known about its prognostic significance. The aim of this study was to evaluate the expression patterns of HEF1 in urinary bladder carcinoma and to investigate its prognostic significance. HEF1 expression was analyzed by immunohistochemistry using tissue microarray. A significant relationship between HEF1 expression and sex, tumor size, number of tumors, invasion depth, lymph node metastasis, and distant metastasis was found, and high expression of HEF1 was associated with worse overall survival when compared to low expression of HEF1. Multivariate analysis showed that HEF1 expression was an independent prognostic factor for overall survival in urinary bladder carcinoma. We investigated HEF1 expression in urinary bladder carcinoma and found that high HEF1 expression was associated with advanced stage, large tumor size, and shortened progression-free survival. Although the biologic function of HEF1 in urinary bladder carcinoma remains unknown, the expression of HEF1 can provide new prognostic information for disease progression.
\end{abstract}

Keywords: human enhancer of filamentation 1, progression-free survival, immunohistochemistry, metastasis, bladder cancer

\section{Introduction}

Bladder cancer is a common malignancy of the urogenital system worldwide. ${ }^{1}$ In 2008 , global estimates suggested that approximately 386,300 new bladder cancer cases were diagnosed. ${ }^{1}$ The vast majority of patients have a $30 \%-70 \%$ recurrence rate, and bladder cancer may progress to invasive cancers in $10 \%-30 \%$ of patients. ${ }^{2,3}$ Therefore, the identification of biomarkers for bladder cancer and the search for molecular mechanisms are critical for the prognosis of bladder cancer.

Human enhancer of filamentation 1 (HEF1), also known as NEDD9 or Cas-L, is a multidomain scaffolding protein of the Cas family; it is also an integral player in normal and pathological cell biology. ${ }^{4-6}$ Functionally, the cell cycle-regulated processing of HEF1 to multiple protein forms differentially targets multiple subcellular compartments. ${ }^{7}$ The HEF1 protein has been implicated in the regulation of cell polarity, adhesion, motility, and invasion in multiple cell types. ${ }^{8,9}$ It acts as a scaffold protein and belongs to a family of Crk-associated substrates that regulates protein complexes controlling invasion and differentiation of cancer. ${ }^{10}$

Elevated expression of HEF1 promotes cancer cell growth, migration, and invasion by activating various signal transduction pathways such as extracellular-signal-regulated
Correspondence: Ying-Yu Ma Key Laboratory of Gastroenterology of Zhejiang Province, Zhejiang Provincial People's Hospital, No I58 Shangtang

Road, Hangzhou, Zhejiang 3I00I4,

People's Republic of China

Tel +86057 I 8589378 I

Fax +86 57। 85893587

Email myy0II525@I63.com 
kinase, p38, focal adhesion kinase (FAK), and Aurora A. .,11-14 In addition, several studies reveal that HEF1 is transcriptionally regulated in response to intracellular or extracellular signals. ${ }^{11}$ Elevated expression of HEF1 has been implicated in a variety of tumor types, including glioblastoma, melanoma, breast cancer, and lung cancers..$^{10,11,15-18}$ These data support the fact that HEF1 is a tumor-promoting factor, and its elevated expression in tumors correlates with poor prognosis and treatment resistance. ${ }^{4,5,14,17}$ In colorectal cancer, HEF 1 is a $\mathrm{T}$ cell factor-beta-catenin target gene and its elevated expression correlates with increased migration and cancer progression. ${ }^{4}$ HEF1 is upregulated in lung adenocarcinoma, and overexpression of the HEF1 protein has been strongly correlated with staging, differentiation grade, and tumor size in lung adenocarcinoma, which all demonstrated a poor prognosis. ${ }^{10} \mathrm{HEF} 1$ overexpression is associated with aggressive breast cancers, including ERBB2-overexpressing subtypes. ${ }^{15}$ These studies implicated that HEF1 may have a promotive effect for the carcinogenic process. To date, the prognostic value of HEF1 in urinary bladder carcinoma has not been investigated.

To assess the prognostic value of HEF 1 in urinary bladder carcinoma, we performed an immunohistochemical study using a tissue microarray (TMA) method.

\section{Materials and methods Fresh samples of bladder cancer tissue}

Thirty fresh bladder cancer specimens from patients with bladder cancer and five normal tissues from cystectomy were acquired from the Zhejiang Provincial People's Hospital (Hangzhou, People's Republic of China) from January 2011-December 2013. After surgical removal, the tissues were frozen immediately in liquid nitrogen and stored at $-80^{\circ} \mathrm{C}$ until used.

\section{Bladder carcinoma tissue microarray construction}

Written informed consent was obtained from all participants involved. We obtained ethics approval from the ethics committee of Zhejiang Provincial People's Hospital. A total of 175 of 245 consecutive patients who underwent radical cystectomy for bladder carcinoma at Zhejiang Provincial People's Hospital between January 1998 and January 2006 were included in this retrospective study; only specimens of primary diagnoses as bladder cancer obtained by radical cystectomy were included. Tissues had been formalin-fixed, paraffin-embedded, and diagnosed clinically and histopathologically at the Departments of Urology and Pathology. The patient cohort consisted of 117 males and 58 females, with a median age of 61.5 years (range: $35-78$ ) at the time of surgery. All patients had follow-up records for $>5$ years. The follow-up deadline was December 2006. The survival time was calculated from the date of surgery to the follow-up deadline or the date of death. Death was caused mainly by carcinoma recurrence or metastasis. Forty-two noncancerous human bladder tissues were obtained from radical cystectomy of adjacent bladder carcinoma margins $>5 \mathrm{~cm}$. Samples were brought into a TMA format, as previously described. ${ }^{19}$ Briefly, core tissue biopsies ( $2 \mathrm{~mm}$ in diameter) were obtained from the targeted area of each donor tissue block, which was arranged in recipient paraffin blocks (tissue array blocks) using a TM instrument (TM-1, Shanghai Jianglai Biotechnology, Shanghai, People's Republic of China); in small specimens, 1-3 cores were obtained, based on tissue amount. Staining results from different intratumoral areas in various tumors showed reliable consistency; therefore, a single core was sampled in each case. A qualified sample was defined as a tumor occupying more than $10 \%$ of the core area. Each block contained six noncancerous bladder mucosa as the internal controls. Consecutive $4 \mu \mathrm{m}$-thick sections were cut from each tissue array block, deparaffinized, and dehydrated.

\section{Real-time polymerase chain reaction analysis}

Briefly, total ribonucleic acid (RNA) was extracted from tissues using TRIzol ${ }^{\circledR}$ (Thermo Fisher Scientific, Waltham, MA, USA) according to the manufacturer's instructions. A total of $2 \mu \mathrm{g}$ of RNA was reverse-transcribed using the SuperScript ${ }^{\circledR}$ II RNase-Reverse Transcriptase System (Thermo Fisher Scientific). The complementary deoxyribonucleic acid (cDNA) was then subjected to real-time polymerase chain reaction with specific primers for $H E F 1$. A $0.4 \mu \mathrm{L}$ cDNA, 0.4 $\mu \mathrm{mol} / \mathrm{L}$ forward primer and $0.4 \mu \mathrm{mol} / \mathrm{L}$ reverse primer were added to SYBR ${ }^{\circledR}$ Premix Ex Taq ${ }^{\mathrm{TM}}$ (Takara Bio Inc., Shiga, Japan) in a total volume of $25 \mu \mathrm{L}$. The amplification protocol was used as follows: denatured at $95^{\circ} \mathrm{C}$ for 4 minutes; and then followed by 40 cycles of $95^{\circ} \mathrm{C}$ for 10 seconds, $55^{\circ} \mathrm{C}$ for 20 seconds, and $72^{\circ} \mathrm{C}$ for 20 seconds. The sequence of the forward primer for $H E F 1$ was $5^{\prime}$-CCG AGG CGT TCA GTT TCT T- $3^{\prime}$, and that of the reverse primer was 5'-TTT AGC ATC TGG CGG GTT AT-3'. The sequence of the primers used for glyceraldehyde 3-phosphate dehydrogenase (GAPDH) was 5'-TGA AGG TCG GAG TCA ACG G-3' (forward) and 5'-CTG GAA GAT GGT GAT GGG ATT-3' (reverse; Thermo Fisher Scientific). The relative amount of HEF1 messenger RNA (mRNA) to GAPDH was calculated as the average $2^{-\Delta \mathrm{Ct}}$ where $\Delta \mathrm{Ct}$ (cycle threshold $)=\mathrm{Ct}-\mathrm{Ct}_{\mathrm{GAPDH}}$. 


\section{Immunohistochemistry}

Immunohistochemistry was performed to study the altered protein expression in 42 noncancerous bladder tissue controls and 175 bladder carcinoma tissues. In brief, TMA slides were baked at $60^{\circ} \mathrm{C}$ for 2 hours followed by deparaffinization with xylene, and rehydrated graded alcohol. The sections were submerged in ethylenediamine tetraacetic acid antigenic retrieval buffer and microwaved for antigen retrieval. They were then treated with $3 \%$ hydrogen peroxide in methanol to quench endogenous peroxidase activity, followed by incubation with $1 \%$ bovine serum albumin to reduce background nonspecific binding. Sections were incubated with rabbit anti-HEF1 (Epitomics - an Abcam Company, Burlingame, CA, USA) overnight at $4{ }^{\circ} \mathrm{C}$. Negative controls were performed by replacement of the primary antibody with phosphate buffered saline. After washing, tissue sections were treated with a secondary antibody. Slides were stained with 3, 3-diaminobenzidine and counterstained with hematoxylin, and they were then dehydrated and mounted.

\section{Evaluation of immunostaining intensity}

The HEF1 proteins were immunohistochemically stained yellowish-brown in the cytoplasm of the tumor cells. The degree of immunostaining was reviewed by two observers who were blinded to the clinical data; they independently scored the immunostaining based on the intensity of staining and the percentage of HEF1 immunoreactive cells. In case of a discrepancy, a consensus score was chosen for evaluation. Staining intensity was graded according to the following criteria: 0 (no staining); 1 (weak staining = light yellow); 2 (moderate staining = yellowish brown); and 3 (strong staining $=$ brown). The staining percentage was graded according to the proportion of positively stained tumor cells, as follows: 0 for $<5 \%$ positive tumor cells; 1 for $6 \%-25 \%$ positive tumor cells; 2 for $26 \%-50 \%$ positive tumor cells; and 3 for $>51 \%$ positive tumor cells. The staining intensity and the percent immunoreactivity scores were then multiplied to obtain a composite score. We used this method of assessment to evaluate HEF1 expression in human nontumor mucosa and malignant lesions by determining the staining index with scores of $0,1,2,3,4,6$, or 9 . An optimal cut-off value was identified as follows: a staining index score of $\geq 4$ was used to define tumors with high HEF1 expression; and a staining index score of $\leq 3$ was used to indicate low HEF1 expression.

\section{Statistical analysis}

All statistical analyses were performed using the Statistical Package for the Social Sciences (SPSS version 16.0 for
Windows; IBM Corporation, Armonk, NY, USA). To assess the relationships between the expression of HEF1 and the clinicopathological parameters of the patients with bladder carcinoma, categorical data were studied using the $\chi^{2}$ or Fisher's exact test. Survival curves were estimated using the Kaplan-Meier method, and the log-rank test was used to calculate differences between the curves. Multivariate survival analysis using the Cox proportional hazards regression model was performed to assess the predictors related to survival. Correlation coefficients between protein expression and clinicopathological features were estimated using the Spearman correlation method. All $P$-values were two-sided and a $P$-value $<0.05$ was considered statistically significant.

\section{Results \\ Detection of HEFI mRNA expression}

Real-time polymerase chain reaction results also showed that $H E F 1$ mRNA was significantly upregulated in bladder cancer as compared with that of normal tissues $(P=0.012$, Wilcoxon test; Figure 1).

\section{Overexpression of HEFI in bladder carcinoma tissues}

The immunostaining of HEF1 was mainly located in the cytoplasm of the tumor cells (Figure 2). The expression of the HEF1 protein was detected as negative in all 42 noncancerous bladder mucosa. High expression of HEF1 was detected in $62.9 \%(110 / 175)$ of cases, and low expression was detected in $37.1 \%(65 / 175)$ of cases. A graphical form of the score values of the immunostaining of HEF1 expression in tissues is shown in Figure 3. The HEF1 expression in bladder carcinomas was significantly higher than that in the noncancerous bladder mucosa $(P<0.001)$.

\section{Correlation between HEFI expression and clinicopathological features}

The expression of HEF1 in bladder carcinoma was significantly associated with sex, tumor size, number of tumors, invasion depth, lymph node metastasis, and distant metastasis, but it had no association with age and vessel invasion (Table 1). Expression of HEF1 in bladder carcinoma patients with $>3 \mathrm{~cm}$ tumor size, deep tumor invasion (T2-T4), number of tumors, lymph node metastasis, and distant metastasis was significantly higher than in those with superficial tumor invasion ( $\mathrm{Ta}-\mathrm{T} 1)$, and in those without lymph node metastasis and distant metastasis, respectively (Table 1). The detection rate of HEF1 was $83.6 \%$ (51/61) in bladder carcinoma 


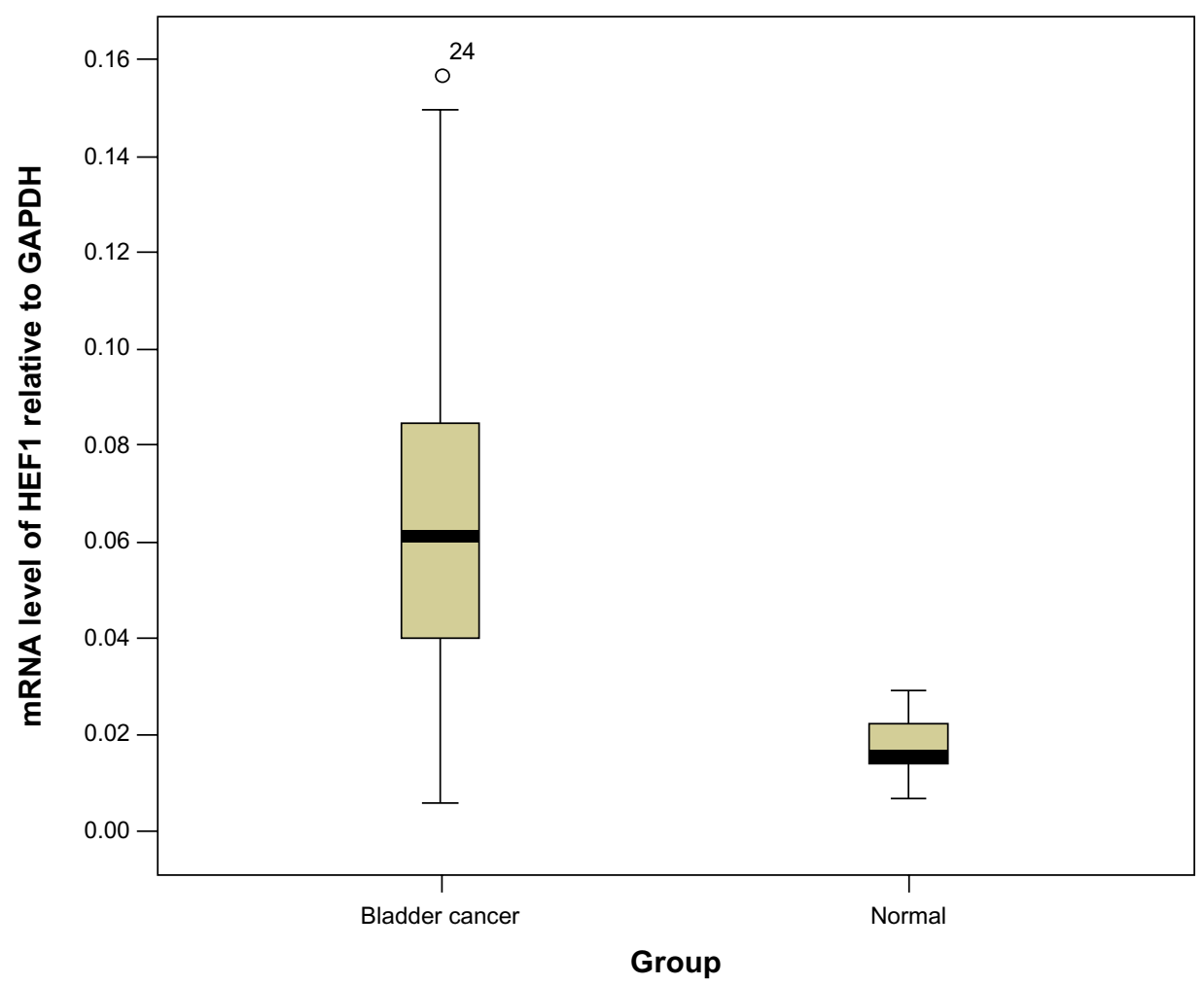

Figure I Reverse transcription-polymerase chain reaction for HEFI expression by using HEFI-specific primers with GAPDH as an internal control. Note: Black area represents median value, the upper and lower edge represent the upper and lower quartile of the box.

Abbreviations: mRNA, messenger RNA; HEFI, Human enhancer of filamentation I; GAPDH, glyceraldehyde 3-phosphate dehydrogenase.
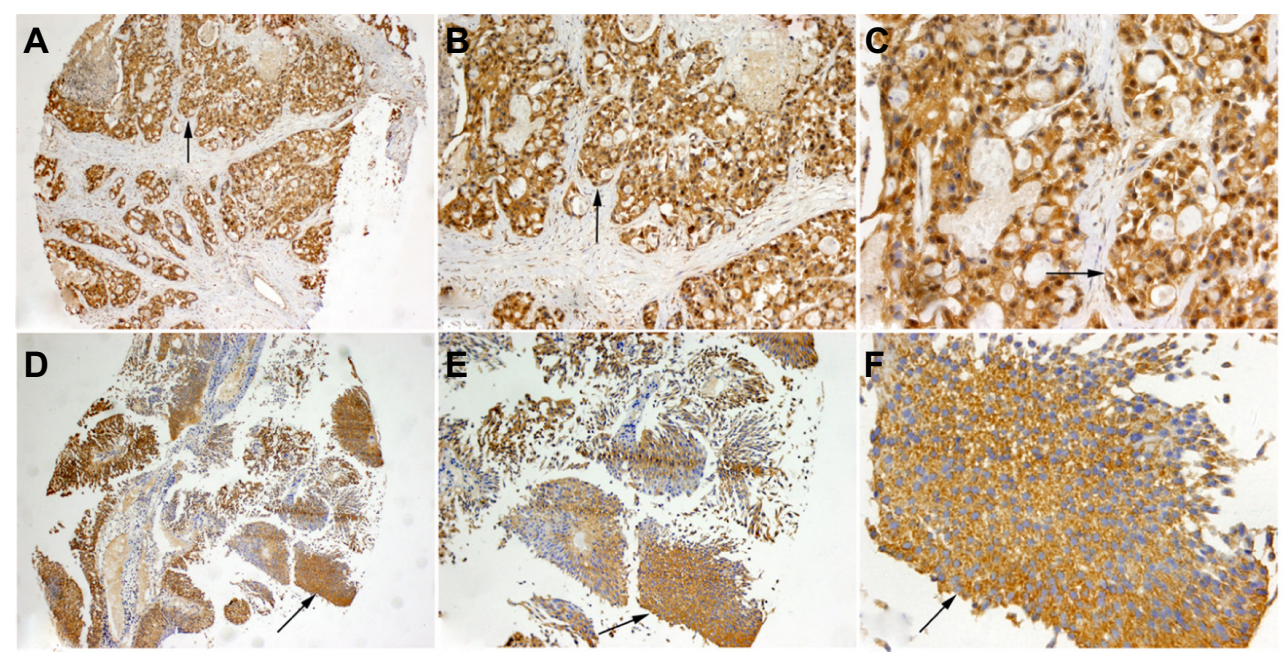

G
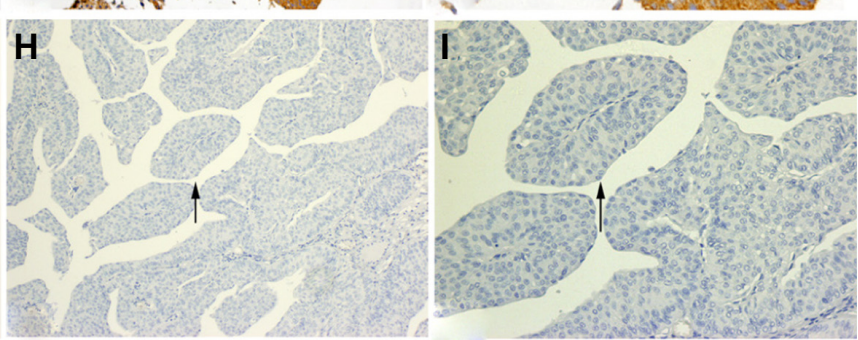

Figure 2 Immunohistochemical staining of HEFI in normal and cancerous bladder tissue.

Notes: (A-C) Strong staining (brown granules, mainly in the cytoplasm) in muscle-invasive urinary bladder carcinoma ( $\uparrow$ ). (D-F): strong staining in nonmuscle-invasive urinary bladder carcinoma $(\uparrow)$. (G-I): Negative control for immunostaining of HEFI ( $\uparrow$ ), with phosphate buffered saline replacing the primary antibody against HEFI. Magnification: the original magnification was $(\mathbf{A}, \mathbf{D}$ and $\mathbf{G}) \times 40,(\mathbf{B}, \mathbf{E}$ and $\mathbf{H}) \times 100$, and $(\mathbf{C}, \mathbf{F}$ and $\mathbf{I}) \times 400$.

Abbreviation: HEFI, Human enhancer of filamentation I. 


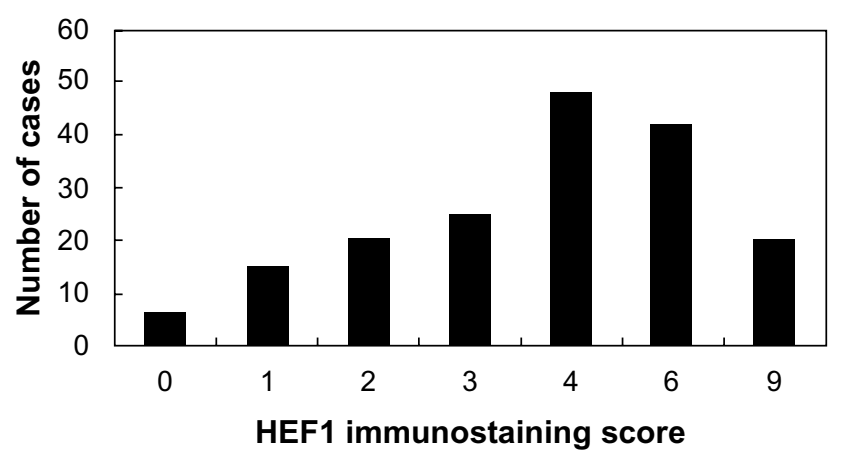

Figure 3 A graphical form of the score values of the immunostaining of HEFI expression in tissues.

Abbreviation: HEFI, human enhancer of filamentation I.

specimens of tumor size $\geq 3 \mathrm{~cm}$, which was higher than that in specimens of tumor sizes $<3 \mathrm{~cm}(51.8 \%, 59 / 114$; $P<0.001)$. The detection rate of HEF1 was $68.1 \%(94 / 138)$ in bladder carcinoma specimens of multiple tumors, which was higher than that in specimens of single tumors $(43.2 \%$, $16 / 37 ; P=0.005)$. HEF1 was detected in $81.0 \%(34 / 42)$ of bladder cancer specimens with lymph node metastasis, which was higher than in specimens without lymph node metastasis (57.1\%, 76/133; $P=0.005)$. The detection rate of HEF1 was $84.2 \%(16 / 19)$ in specimens with distant metastasis, which

Table I Relationship between HEFI expression and the pathological parameters of bladder cancer

\begin{tabular}{|c|c|c|c|c|}
\hline \multirow[t]{2}{*}{ Clinical parameters } & \multicolumn{4}{|c|}{ HEF I expression } \\
\hline & Low & High & $x^{2}$ & $P$-value \\
\hline Sex & & & 12.278 & 0.000 \\
\hline Male & $54(46.2 \%)$ & $63(53.8 \%)$ & & \\
\hline Female & II (19.0\%) & 47 (81.0\%) & & \\
\hline Age (years) & & & 0.001 & 0.971 \\
\hline$<60$ & $25(37.3 \%)$ & $42(62.7 \%)$ & & \\
\hline$\geq 60$ & $40(37.0 \%)$ & $68(63.0 \%)$ & & \\
\hline Tumor size & & & 17.268 & 0.000 \\
\hline$<3 \mathrm{~cm}$ & $55(48.2 \%)$ & 59 (51.8\%) & & \\
\hline$\geq 3 \mathrm{~cm}$ & $10(16.4 \%)$ & 51 (83.6\%) & & \\
\hline Multiplicity & & & 7.731 & 0.005 \\
\hline Single & 21 (56.8\%) & $16(43.2 \%)$ & & \\
\hline Multiple & 44 (31.9\%) & 94 (68.1\%) & & \\
\hline Invasion depth & & & 22.174 & 0.000 \\
\hline $\mathrm{Ta}-\mathrm{I}$ & 37 (60.7\%) & 24 (39.3\%) & & \\
\hline $\mathrm{T} 2-\mathrm{T} 4$ & $28(24.6 \%)$ & 86 (75.4\%) & & \\
\hline Lymph node metastasis & & & 7.751 & 0.005 \\
\hline No & 57 (42.9\%) & 76 (57.I\%) & & \\
\hline Yes & $8(19.0 \%)$ & $34(81.0 \%)$ & & \\
\hline Distant metastasis & & & 4.163 & $0.04 I$ \\
\hline No & $62(39.7 \%)$ & 94 (60.3\%) & & \\
\hline Yes & $3(15.8 \%)$ & $16(84.2 \%)$ & & \\
\hline Vessel invasion & & & 0.173 & 0.678 \\
\hline Negative & 57 (37.7\%) & 94 (62.3\%) & & \\
\hline Positive & 8 (33.3\%) & $16(66.7 \%)$ & & \\
\hline
\end{tabular}

Abbreviation: HEFI, human enhancer of filamentation I. was higher than in specimens without distant metastasis (60.3\%, 94/156; $P=0.041)$. HEF1 was detected in $39.3 \%$ $(24 / 61)$ of deep tumor invasion (T2-T4), which was lower than in superficial tumor invasion (Ta-T1) samples, where it was detected in $75.4 \%$ of samples $(86 / 114 ; P<0.001)$. Spearman's correlation coefficient of HEF1 expression with the number of tumors, depth of invasion, vessel invasion, lymph node metastasis, and distant metastasis of the tumor were $0.232,0.361,0.254,0.155$ and $0.253(P<0.05)$, respectively.

\section{Survival analysis}

The mean survival time in patients with a high expression of HEF1 was $36.74 \pm 1.49$ months, which was significantly lower than in patients with a low expression of HEF1 (55.26 \pm 1.24 months; $P<0.001)$. Kaplan-Meier survival statistics showed that high expression of HEF1 was associated with worse overall survival when compared to low expression of HEF1 ( $P<0.001$; Figure 4). Factors with possible prognostic effects in bladder carcinoma were analyzed by Cox regression analysis. The statistical analysis showed that the expression of HEF 1 was an independent prognostic factor in patients with bladder carcinoma ( $P=0.001$; Table 2$)$.

\section{Discussion}

We have revealed the prognostic value of HEF1 in urinary bladder carcinoma. HEF1 expression has been found to be more frequently detected in advanced stages of urinary bladder carcinoma with shortened progression-free survival. Meanwhile, we showed a significant correlation of HEF1 expression with sex, tumor size, number of tumors, invasion depth, lymph node metastasis, and distant metastasis. This finding is further in line with the known association of HEF1 overexpression with other tumor types. ${ }^{4,10,11}$ Furthermore, we showed a significant association of HEF1 in urinary bladder carcinoma with a worse overall survival. However, results concerning the prognostic significance of HEF1 expression are conflicting. Overexpression of HEF1 has been shown to be an independent prognostic factor associated with worse overall survival in lung adenocarcinoma, breast cancer, and melanoma, whereas some researchers argue that HEF1 may play a more complex role in tumor invasion and metastasis. ${ }^{4,10,11,15,20,21}$

The HEF1 protein lacks any known enzymatic function, but contains many functional modules for protein interaction, leading to its classification as a scaffolding protein., ${ }^{9,1022-24}$ Proteins that functionally or physically interact with HEF1 play direct roles in promoting tumor invasion. ${ }^{21}$ Furthermore, 


\section{Survival functions}

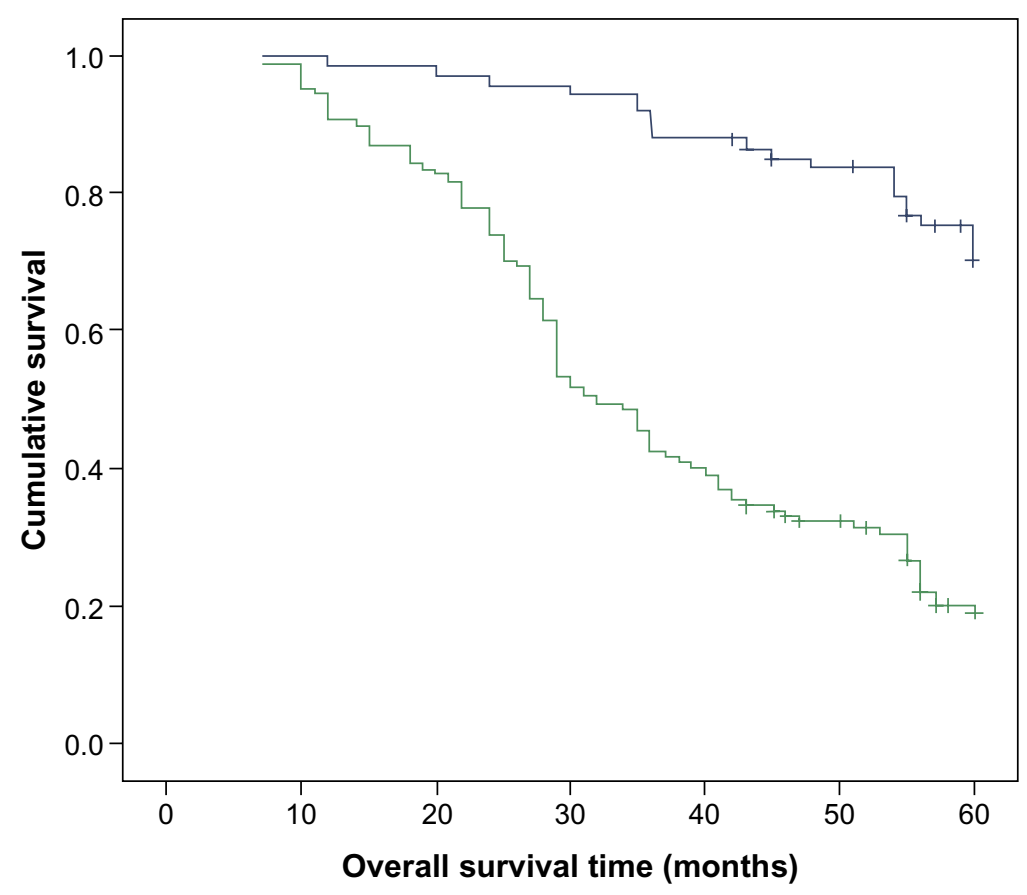

HEF1

$\neg$ Low

$\neg$ High

+ Low-censored

- High-censored

Figure 4 Kaplan-Meier survival curves of urinary bladder carcinoma patients with different levels of HEFI expression.

Abbreviation: HEFI, human enhancer of filamentation I.

HEF1 expression and activation are regulated by the cell cycle and by multiple cues provided by receptors for diffusible and attachment-related stimuli. ${ }^{11}$ Because of this complex signaling "hub" function, elevated HEF1 expression is poised to influence cell growth controls in many different ways. ${ }^{15}$ Significantly, extensive characterization of HEF1 over the past decade has revealed that changes in HEF1 status HEF1 status may play important role in metastasis. ${ }^{21}$ Our study is the first in which the prognostic significance of HEF1 in urinary bladder carcinoma has rationally been evaluated.

The molecular functional basis for HEF1 may act as multifunctional coordinator of invasion, apoptosis, and cell cycle control..$^{5,7,11,25}$ A recent study that has provided in vivo evidence shows that HE supports the activation of oncogenic signaling pathways, including Src, extracellularsignal-regulated kinase, and protein kinase B (AKT) in breast cancer development. ${ }^{6}$ In colorectal cancer, HEF1 is a novel target of Wnt signaling, and elevated expression promotes increased colonic cell migration and cancer progression. ${ }^{4}$ HEF1 is also a specific effector of the prooncogenic FAK kinase, and is required for the migration and invasion of aggressive glioblastomas. ${ }^{17} \mathrm{HEF} 1$ was found to be a central component of integrin-dependent signaling cascades that activate the FAK and Src kinases to promote cell migration, and it is also involved in communication through Shc and other proteins to the Ras signaling cascades. ${ }^{26}$ In urinary bladder

Table 2 Multivariate analysis of the correlation between the clinicopathological parameters and survival time of patients with bladder cancer

\begin{tabular}{|c|c|c|c|c|c|}
\hline Covariates & Coefficient & $\begin{array}{l}\text { Standard } \\
\text { error }\end{array}$ & HR & $\begin{array}{l}95.0 \% \mathrm{Cl} \\
\text { for } \mathrm{HR}\end{array}$ & $P$-value \\
\hline Age range ( $>60$ years versus $\leq 60$ years) & 0.102 & 0.228 & 1.108 & $0.709-1.73 \mid$ & 0.654 \\
\hline Tumor size $(\geq 3 \mathrm{~cm}$ versus $<3 \mathrm{~cm})$ & 0.126 & 0.237 & 1.134 & $0.897-2.179$ & 0.139 \\
\hline Number of tumors (single versus multiple) & 0.320 & 0.281 & 1.377 & $0.794-2.387$ & 0.255 \\
\hline Lymph node metastasis (positive versus negative) & 0.663 & 0.286 & 1.942 & $1.109-3.398$ & 0.020 \\
\hline Vessel invasion (positive versus negative) & -0.123 & 0.314 & 0.884 & $0.478-1.636$ & 0.695 \\
\hline Distant metastasis (positive versus negative) & 0.709 & 0.270 & 2.032 & I.198-3.447 & 0.009 \\
\hline HEFI expression (high versus low) & 1.011 & 0.299 & 2.747 & $1.528-4.938$ & 0.001 \\
\hline Depth of invasion (T2-T4 versus $\mathrm{Ta}-\mathrm{TI})$ & 1.152 & 0.308 & 3.164 & I.729-5.788 & 0.000 \\
\hline
\end{tabular}

Abbreviations: $\mathrm{HR}$, hazard ratio; $\mathrm{Cl}$, confidence interval; $\mathrm{HEFI}$, human enhancer of filamentation I. 
carcinoma, our present study found that HEF1 expression is related to an aggressive phenotype; therefore, we assume a direct oncogenic role.

Invasion depth, lymph node metastasis, and distant metastasis have been considered as the most important factors in the survival, management, and prognosis of bladder cancer patients, as well as of those with other carcinomas. ${ }^{27-29}$ In our study, we found that the overexpression of HEF1 was significantly associated with the poor prognosis of patients with bladder cancer, and that the expression of HEF1 was an independent prognostic factor. Other factors significantly correlated with the survival of the patients including sex, tumor size, number of tumors, invasion depth, lymph node metastasis, and distant metastasis. The association of HEF1 expression in urinary bladder carcinoma with an advanced stage and a poor outcome points toward its possible role as an effective marker for predicting therapeutic outcomes, and it is a potential target for anticancer therapy. This suggests that HEF1 may play a role as an objective and effective indicator for the identification of bladder cancer patients who are at high risk for tumor invasion and progression. Our findings are in agreement with earlier reports, ${ }^{4,10}$ in that the overexpression of HEF1 has been implicated as a tumor-promoting factor, and it is associated with a poor prognosis in a variety of tumor types.

\section{Conclusion}

In conclusion, we have shown that in urinary bladder carcinoma, HEF1 expression accompanies advanced stage and is associated with poor overall survival. As an independent prognostic indicator, the expression of HEF1 in advanced stage tumors suggests it plays a possible role during tumor progression, which makes HEF1 a potential target for antibody-mediated treatment in urinary bladder carcinoma.

\section{Acknowledgments}

This work is supported by the Zhejiang Medical College Research Foundation (No 2013XZB01), National Natural Science Foundation of Zhejiang Province (No LQ13H050001), and Medicine and Health Research Foundation of Zhejiang Province (No 2013KYB018).

\section{Author contributions}

QZ participated in the design of the study, collected data, analyzed the results, and drafted the manuscript. HJW participated in the design of the study and performed the statistical analysis. DHZ and GQR carried out the immunochemistry staining and assessed the results. XJH helped to analyze the data and interpret the results. YYM participated in the study design and coordination, revised the manuscript critically, and gave final approval of the version to be published. All authors contributed toward data analysis, drafting and revising the paper and approved the final manuscript.

\section{Disclosure}

The authors report no conflicts of interest in this work.

\section{References}

1. Jemal A, Siegel R, Ward E, et al. Cancer statistics, 2008. CA Cancer J Clin. 2008;58(2):71-96.

2. Dalbagni G, Herr HW. Current use and questions concerning intravesical bladder cancer group for superficial bladder cancer. Urol Clin North Am. 2000;27(1):137-146.

3. Lee R, Droller MJ. The natural history of bladder cancer. Implications for therapy. Urol Clin North Am. 2000;27(1):1-13, vii.

4. LiY, Bavarva JH, Wang Z, et al. HEF1, a novel target of Wnt signaling, promotes colonic cell migration and cancer progression. Oncogene. 2011;30(23):2633-2643.

5. Kim SH, Xia D, Kim SW, Holla V, Menter DG, Dubois RN. Human enhancer of filamentation 1 is a mediator of hypoxia-inducible factor-1alpha-mediated migration in colorectal carcinoma cells. Cancer Res. 2010;70(10):4054-4063.

6. Izumchenko E, Singh MK, Plotnikova OV, et al. NEDD9 promotes oncogenic signaling in mammary tumor development. Cancer Res. 2009;69(18):7198-7206.

7. Law SF, Zhang YZ, Klein-Szanto AJ, Golemis EA. Cell cycle-regulated processing of HEF1 to multiple protein forms differentially targeted to multiple subcellular compartments. Mol Cell Biol. 1998;18(6):3540-3551.

8. Gu JJ, Lavau CP, Pugacheva E, Soderblom EJ, Moseley MA, Pendergast AM. Abl family kinases modulate T cell-mediated inflammation and chemokine-induced migration through the adaptor HEF1 and the GTPase Rap1. Sci Signal. 2012;5(233):ra51.

9. O’Neill GM, Fashena SJ, Golemis EA. Integrin signalling: a new Cas(t) of characters enters the stage. Trends Cell Biol. 2000;10(3):111-119.

10. Chang JX, Gao F, Zhao GQ, Zhang GJ. Expression and clinical significance of NEDD9 in lung tissues. Med Oncol. 2012;29(4):2654-2660.

11. Singh M, Cowell L, Seo S, O’Neill G, Golemis E. Molecular basis for HEF1/NEDD9/Cas-L action as a multifunctional co-ordinator of invasion, apoptosis and cell cycle. Cell Biochem Biophys. 2007;48(1):54-72.

12. Pugacheva EN, Golemis EA. The focal adhesion scaffolding protein HEF1 regulates activation of the Aurora-A and Nek2 kinases at the centrosome. Nat Cell Biol. 2005;7(10):937-946.

13. Dadke D, Jarnik M, Pugacheva EN, Singh MK, Golemis EA. Deregulation of HEF1 impairs M-phase progression by disrupting the RhoA activation cycle. Mol Biol Cell. 2006;17(3):1204-1217.

14. Xia D, Holla VR, Wang D, Menter DG, DuBois RN. HEF1 is a crucial mediator of the proliferative effects of prostaglandin $\mathrm{E}(2)$ on colon cancer cells. Cancer Res. 2010;70(2):824-831.

15. Bradbury P, Mahmassani M, Zhong J, et al. PP2A phosphatase suppresses function of the mesenchymal invasion regulator NEDD9. Biochim Biophys Acta. 2012;1823(2):290-297.

16. Kim M, Gans JD, Nogueira C, et al. Comparative oncogenomics identifies NEDD9 as a melanoma metastasis gene. Cell. 2006;125(7): 1269-1281.

17. Natarajan M, Stewart JE, Golemis EA, et al. HEF1 is a necessary and specific downstream effector of FAK that promotes the migration of glioblastoma cells. Oncogene. 2006;25(12):1721-1732.

18. Tikhmyanova N, Golemis EA. NEDD9 and BCAR1 negatively regulate E-cadherin membrane localization, and promote E-cadherin degradation. PLoS One. 2011;6(7):e22102. 
19. Zhang Q, Ye Z, Yang Q, He X, Wang H, Zhao Z. Upregulated expression of annexin II is a prognostic marker for patients with gastric cancer. World J Surg Oncol. 2012;10:103.

20. Kong C, Wang C, Wang L, et al. NEDD9 is a positive regulator of epithelial-mesenchymal transition and promotes invasion in aggressive breast cancer. PLoS One. 2011;6(7):e22666.

21. O’Neill GM, Seo S, Serebriiskii IG, Lessin SR, Golemis EA. A new central scaffold for metastasis: parsing HEF1/Cas-L/NEDD9. Cancer Res. 2007;67(19):8975-8979.

22. Law SF, Estojak J, Wang B, Mysliwiec T, Kruh G, Golemis EA. Human enhancer of filamentation 1, a novel p130cas-like docking protein, associates with focal adhesion kinase and induces pseudohyphal growth in Saccharomyces cerevisiae. Mol Cell Biol. 1996;16(7): 3327-3337.

23. Minegishi M, Tachibana K, Sato T, Iwata S, Nojima Y, Morimoto C. Structure and function of Cas-L, a 105-kD Crk-associated substraterelated protein that is involved in beta 1 integrin-mediated signaling in lymphocytes. J Exp Med. 1996;184(4):1365-1375.

24. Seo S, Ichikawa M, Kurokawa M. Structure and function of cas-L and integrin-mediated signaling. Crit Rev Immunol. 2006;26(5):391-406.
25. Pugacheva EN, Golemis EA. HEF1-aurora A interactions: points of dialog between the cell cycle and cell attachment signaling networks. Cell Cycle. 2006;5(4):384-391.

26. Singh MK, Izumchenko E, Klein-Szanto AJ, Egleston BL, Wolfson M, Golemis EA. Enhanced genetic instability and dasatinib sensitivity in mammary tumor cells lacking NEDD9. Cancer Res. 2010;70(21):8907-8916.

27. Gschwend JE, Fair WR, Vieweg J. Radical cystectomy for invasive bladder cancer: contemporary results and remaining controversies. Eur Urol. 2000;38(2):121-130.

28. Scrimger RA, Murtha AD, Parliament MB, et al. Muscle-invasive transitional cell carcinoma of the urinary bladder: a population-based study of patterns of care and prognostic factors. Int J Radiat Oncol Biol Phys. 2001;51(1):23-30.

29. Vieweg J, Gschwend JE, Herr HW, Fair WR. Pelvic lymph node dissection can be curative in patients with node positive bladder cancer. J Urol. 1999;161(2):449-454.
OncoTargets and Therapy

\section{Publish your work in this journal}

OncoTargets and Therapy is an international, peer-reviewed, open access journal focusing on the pathological basis of all cancers, potential targets for therapy and treatment protocols employed to improve the management of cancer patients. The journal also focuses on the impact of management programs and new therapeutic agents and protocols on

\section{Dovepress}

patient perspectives such as quality of life, adherence and satisfaction. The manuscript management system is completely online and includes a very quick and fair peer-review system, which is all easy to use. Visit http://www.dovepress.com/testimonials.php to read real quotes from published authors. 